\title{
Comment on: the role of biopsy in the management of patients with presumed diffuse low grade glioma: a systematic review and evidence-based clinical practice guideline
}

\author{
Christoph Schwartz ${ }^{1}$ Friedrich-Wilhelm Kreth ${ }^{1}$
}

Received: 24 December 2015/Accepted: 15 February 2016/Published online: 26 February 2016

(C) Springer Science+Business Media New York 2016

To the Editor,

We have read with interest the review article by Ragel et al. on "The role of biopsy in the management of patients with presumed low grade glioma" recently published in the "TOPIC REVIEW \& CLINICAL GUIDELINES" section of the journal [1]. The authors have analyzed and compared diagnostic yield and accuracy of distinct biopsy techniques within the framework of conventional histologic classification schemes. This approach, however, falls short and cannot be longer used to weigh the pros and cons of different biopsy techniques: It has increasingly become clear that the prognosis of suspected grade II gliomas is not accurately reflected by conventional histological classification [2]. Accordingly, the provided measurements of accuracy are of little help and cannot be linked to valid prognostic evaluation and tailored treatment. Failing to determine the molecular status of the individual tumors might leave patients and their neuro-oncologists with uncertainties regarding prognosis and personalized treatment options. Moreover, conventionally biopsied patients cannot be included in prospective trials demanding stratification for molecular markers. Thus, one of the most important tasks of modern stereotactic neuro-oncology is to provide timely and validly both a molecular and tissue diagnosis enabling a comprehensive characterization of the individual tumor. The paradigm shift towards molecular stereotactic biopsy techniques has already been acknowledged in the literature [3]. It has been shown, for example, that the status of biomarker profiles currently in use is the same throughout the entire viable tumor bulk and therefore

\footnotetext{
Christoph Schwartz

christoph.schwartz@med.uni-muenchen.de

1 Ludwig-Maximilians-University, Munich, Germany
}

can be validly determined from small sized kryo-preserved specimens [3]. Training in stereotactic neurosurgery and molecular stereotactic neuropathology, however, seems to be mandatory to achieve excellent results [3]. We strongly agree that we are currently just at the beginning of new and exciting developments. Tumors will be increasingly screened for their molecular and immunological status initially and over time when they recur after treatment. Molecular biopsy techniques represent a fast, safe, and minimal invasive tool to collect tissue specimens for these important analyses [4].

Compliance with ethical standards

Conflict of interest The authors report no conflict of interest.

\section{References}

1. Ragel BT, Ryken TC, Kalkanis SN, Ziu M, Cahill D, Olson JJ (2015) The role of biopsy in the management of patients with presumed diffuse low grade glioma: a systematic review and evidence-based clinical practice guideline. J Neurooncol 125(3):481-501. doi:10.1007/s11060-015-1866-2

2. Eckel-Passow JE, Lachance DH, Molinaro AM et al (2015) Glioma groups based on $1 \mathrm{p} / 19 \mathrm{q}$, IDH, and TERT promoter mutations in tumors. N Engl J Med 372(26):2499-2508. doi:10. 1056/NEJMoa1407279

3. Eigenbrod S, Trabold R, Brucker D, Erös C, Egensperger R, La Fougere C, Göbel W, Rühm A, Kretzschmar HA, Tonn JC, Herms J, Giese A, Kreth FW (2014) Molecular stereotactic biopsy technique improves diagnostic accuracy and enables personalized treatment strategies in glioma patients. Acta Neurochir (Wien) 156(8):1427-1440. doi:10.1007/s00701-014-2073-1

4. Kunz M, Thon N, Eigenbrod S, Hartmann C, Egensperger R, Herms J, Geisler J, la Fougere C, Lutz J, Linn J, Kreth S, von Deimling A, Tonn JC, Kretzschmar HA, Pöpperl G, Kreth FW (2011) Hot spots in dynamic (18)FET-PET delineate malignant tumor parts within suspected WHO grade II gliomas. Neuro Oncol 13(3):307-316. doi:10.1093/neuonc/noq196 